\title{
A Japanese Study Assessing Glycemic Control with Use of IDegAsp Co-formulation in Patients with Type 2 Diabetes in Clinical Practice: The JAGUAR Study
}

\author{
Shizuka Kaneko (D) · João D. da Rocha Fernandes · Yuiko Yamamoto • \\ Jakob Langer · Mads Faurby
}

Received: November 12, 2020 / Accepted: January 12, 2021 / Published online: February 9, 2021

(C) The Author(s) 2021

\begin{abstract}
Introduction: The aim of this study was to evaluate the glycemic control and safety of insulin degludec/insulin aspart (IDegAsp) coformulation in Japanese patients with type 2 diabetes (T2D) in a real-world clinical setting, including elderly patients (aged $>75$ years).

Methods: Patients ( $\geq 18$ years) diagnosed with $\mathrm{T} 2 \mathrm{D}$, previously treated with insulin were included from the Japanese Medical Data Vision database. Baseline data were taken at the index date, defined as the first IDegAsp prescription claim. Change in glycated hemoglobin $\left(\mathrm{HbA}_{1 \mathrm{c}}\right)$ at 12 months was estimated using a mixed model repeated measures analysis. The proportion of patients achieving target $\mathrm{HbA}_{1 \mathrm{c}}<8.0 \%$ without experiencing hypoglycemia (identified by International Classification of Disease codes)
\end{abstract}

Supplementary Information The online version contains supplementary material available at https:// doi.org/10.1007/s12325-021-01623-y.

S. Kaneko $(\bowtie)$

Division of Diabetes/Endocrinology/Lifestyle-

Related Disease, Takatsuki Red Cross Hospital,

Takatsuki, Japan

e-mail: ayamoesk3218@takatsuki.jrc.or.jp

J. D. da Rocha Fernandes · M. Faurby

Novo Nordisk A/S, Vandtårnsvej, Søborg, Denmark

Y. Yamamoto $\cdot$ J. Langer

Novo Nordisk Pharma Ltd, Tokyo, Japan was calculated at 12 months (365 \pm 90 days) after baseline.

Results: Overall, 10,798 patients were included, 3940 were aged $>75$ years, and 913 had baseline $\mathrm{HbA}_{1 \mathrm{c}}$ values available. Switching to IDegAsp was associated with significantly improved $\mathrm{HbA}_{1 \mathrm{c}}$ values at 12 months $(-1.23 \%$ $\left.[-1.43,-1.02]_{95 \% \mathrm{CI}}, p<0.001\right)$ versus baseline. Moreover, relative to baseline, a significantly greater proportion of patients achieved $\mathrm{HbA}_{1 \mathrm{c}}<8.0 \%$ without hypoglycemia at 12 months, relative rate (RR) 1.30 [1.15, $1.45]_{95 \% \mathrm{CI}}, p<0.001$. Results were similar for patients aged $\leq 75$ years and aged $>75$ years; $66 \%$ and $64 \%$ of patients, respectively, achieved $\mathrm{HbA}_{1 \mathrm{c}}<8.0 \%$ without hypoglycemia at 12 months.

Conclusion: Switching from insulin to IDegAsp co-formulation was associated with significantly improved glycemic control and a reduction in hypoglycemia rate during 12 months of follow-up in Japanese patients with T2D, including those aged $>75$ years.

Keywords: Elderly; Hypoglycemia; IDegAsp; Insulin; Japan; Real-world; Type 2 diabetes 


\section{Key Summary Points}

Why carry out this study?

Achievement of optimum glycemic control and prevention of diabetic complications are key goals of type 2 diabetes (T2D) management, which often require insulin treatment.

Older patients may need treatment intensification, which can increase the risk of hypoglycemia.

This study aimed to investigate glycemic control and incidence of hypoglycemia in Japanese patients with T2D who initiate insulin degludec/insulin aspart (IDegAsp) co-formulation in a real-world clinical setting, including elderly patients (aged $>75$ years).

\section{What was learned from the study?}

Switching from insulin to IDegAsp coformulation was associated with significantly improved glycemic control and a reduction in hypoglycemia rate during 12 months of follow-up in Japanese patients with T2D.

Results were similar for patients aged $\leq 75$ years and aged $>75$ years.

\section{DIGITAL FEATURES}

This article is published with digital features, including a summary slide, to facilitate understanding of the article. To view digital features for this article go to https://doi.org/10.6084/ m9.figshare.13562330.

\section{INTRODUCTION}

The objectives of diabetes management are to achieve optimum glycemic control and to prevent the progression of diabetic complications
[1]. Older age and higher glycated hemoglobin $\left(\mathrm{HbA}_{1 \mathrm{c}}\right)$ levels are among the established risk factors for macro- and microvascular complications in type 2 diabetes (T2D), and their association has been confirmed in Japanese people with T2D [2]. As a result of the progressive nature of T2D, insulin treatment can often be a requirement for people of all ages to achieve glycemic control $[3,4]$.

Compared with younger people, older people (aged $\geq 75$ years) with T2D typically have more comorbidities, which can impair their ability to perform diabetes self-care [5]. A further consideration when treating older patients is that many will have had a longer duration of diabetes than younger patients and may therefore require more intensified, complex regimens, which may increase the risk of hypoglycemia [6]. In addition, the symptoms of hypoglycemia can be particularly debilitating in older people because of frailty, which can result in increased risk of bone fracture, head injuries, hospital admissions, and long-term care placements due to falls [7].

Insulin degludec/insulin aspart (IDegAsp) is a co-formulation of insulin degludec (degludec, 70\%) and insulin aspart (IAsp, 30\%), in a single injection, and is administered once or twice daily with main meals [8]. The basal component, degludec, has a flat pharmacokinetic profile over $24 \mathrm{~h}$ at steady state, and provides a stable, long-lasting, glucose-lowering effect. The bolus component, IAsp, has a rapid onset and short duration of action and reduces glucose excursions at mealtimes immediately after injection [9].

The efficacy and safety profiles of IDegAsp have been demonstrated in people with T2D through the BOOST clinical trial program [10-13]. IDegAsp once daily has been evaluated in insulin-naïve Japanese patients with T2D, in which a significant estimated treatment difference in $\mathrm{HbA}_{1 \mathrm{c}}$ of $-0.28 \%(p<0.01)$ and comparable rates of overall and nocturnal hypoglycemia were observed compared with insulin glargine $100 \mathrm{U} / \mathrm{mL}$ [12]. In a recent post hoc analysis in a subgroup of patients aged $\geq 65$ years from two phase 3 BOOST trials, IDegAsp twice daily (BID) was found to provide effective glycemic control comparable with the 
effects of biphasic insulin aspart 30 (BIAsp 30) BID [14]. Furthermore, no significant differences were observed between the treatment groups in overall confirmed or nocturnal hypoglycemic events. Similar findings were observed in the Japanese cohort of BOOST INTENSIFY ALL [14].

Randomized controlled trials (RCTs), and the findings from those described above, are, however, limited by their study design and patient inclusion criteria [15]. Therefore, it is important to determine whether the clinical effects of IDegAsp demonstrated in RCTs are generalizable to the real-world clinical setting. The aim of this study was to investigate glycemic control and incidence of hypoglycemia in Japanese patients with T2D who initiate IDegAsp in a real-world clinical setting. In addition, this study aimed to evaluate the glycemic control and incidence of hypoglycemia in elderly patients with T2D (aged $>75$ years) using IDegAsp, an age group for which there are limited RCT data. To our knowledge, no real-world data on the effects or safety of IDegAsp in elderly Japanese patients have been published, despite older people (aged $\geq 65$ years) accounting for $28.1 \%$ of the population in Japan and this proportion having been predicted to increase in the future [16]. Finally, elderly patients form an important population as they are more susceptible to hypoglycemia because of an increased risk of impaired counter-regulatory responses to hypoglycemia, and they have a lower threshold of autonomic symptoms of hypoglycemia, resulting in hypoglycemia unawareness [17].

\section{METHODS}

\section{Study Design}

This was a retrospective database study using secondary data obtained from a medical and pharmacy claims database provided by the Medical Data Vision Co Ltd (MDV; Tokyo, Japan) in October 2018. The MDV database comprises inpatient and outpatient administrative data from more than 300 hospitals in Japan, as well as selected laboratory test results [18]. Overall, at the time of study (October
2018) the database comprised data from $2,325,288$ patients with a diagnosis of T2D [18].

Hypoglycemic events were taken from the administrative database and identified by the billable International Classification of Diseases (ICD), tenth edition, clinical modification (CM) (ICD-10-CM) codes (see Supplementary Material).

\section{Study Population}

People considered eligible for inclusion in the analysis were aged $\geq 18$ years and had a diagnosis of T2D (ICD code E11 subtypes thereof [Supplementary Material]), with no diagnosis of type 1 diabetes. People were required to have started treatment with IDegAsp (at the index date; defined as the first IDegAsp prescription claim) and have had at least one prescription claim for insulin within the period 180 days prior to the index date. There were no restrictions on the use of concomitant antidiabetic medication.

\section{Ethical Consideration}

For this retrospective database study, all data for analysis were extracted from a pre-existing anonymized database and permission was granted to access the data and to use them for publication purposes. For the usage of de-identified secondary data, ethical approval and informed consent do not apply according to the Japanese Ethical Guidelines for Medical and Health Research Involving Human Subjects [19].

\section{Outcomes}

Change from baseline (index date) in $\mathrm{HbA}_{1 \mathrm{c}}$ at 12 months after IDegAsp initiation was estimated for patients with at least one follow-up measurement in addition to their baseline $\mathrm{HbA}_{1 \mathrm{c}}$. Baseline values of $\mathrm{HbA}_{1 \mathrm{c}}$ and body mass index (BMI) were taken in the 180 days prior to the index date; if multiple assessments were available, the value closest to the index date was selected as the baseline value. 
The proportion of patients with an $\mathrm{HbA}_{1 \mathrm{c}}$ of $<8.0 \%,<7.5 \%$, or $<7.0 \%$ at the 12 -month time point was calculated for patients with available baseline and follow-up data. The 12-month data were defined as data recorded $365 \pm 90$ days after the index date. This range was used to allow for a sufficient number of patients with measurements recorded for inclusion in the analysis. Hypoglycemia outcomes included the proportion of patients experiencing at least one hypoglycemic event, and the difference in rates of hypoglycemic events after switching to IDegAsp, comparing baseline data with the available 12-month data. The hypoglycemia events included in the analysis were those identified by billable ICD-10-CM codes [20] (see Supplementary Material for list of codes and their descriptions). These hypoglycemic events justified admission to an acute care hospital.

The proportion of patients achieving $\mathrm{HbA}_{1 \mathrm{c}}<8.0 \%,<7.5 \%$, or $<7.0 \%$ without experiencing hypoglycemia was also assessed. The proportion of patients with at least one hypoglycemic event in the 365 days after the index date (12-month data) was compared with the available data 365 days prior to the index date.

\section{Statistical Analysis}

Least-squares (LS) mean differences from baseline in $\mathrm{HbA}_{1 \mathrm{c}}$ at 12 months were calculated using a mixed model repeated measurements (MMRM) analysis, for which time was included as a fixed factor in months after the index date; an unstructured covariance matrix was used in the analyses. Covariates included in the MMRM analysis were baseline $\mathrm{HbA}_{1 \mathrm{c}}$, time from baseline (grouped by month), previous insulin treatment, age, gender, duration of $\mathrm{T} 2 \mathrm{D}$, and body weight.

The binary outcomes were analyzed by calculating the risk ratio and associated 95\% confidence intervals using a normal distribution approximation. In cases of zero cell count in the calculations of estimates of risk ratios, 0.5 was added to all cell frequencies. All other analyses were as observed, with no imputation of missing data.

For the analysis of hypoglycemia at 12 months, the number of events 365 days post index were compared with the number of events 365 days prior to the index.

Stratified analysis was conducted to assess all outcomes in patients aged $\leq 75$ years and patients aged $>75$ years.

\section{RESULTS}

\section{Demographics and Baseline Characteristics}

Of the 2,325,288 patients with T2D in the MDV database, 10,798 were previously treated with insulin and therefore included in the study (see Fig. S1 in the Supplementary Material). In total, 6858 patients $(63.5 \%)$ were aged $\leq 75$ years and $3940(36.5 \%)$ were aged $>75$ years.

Demographics and baseline characteristics are shown in Table 1. The mean (standard deviation [SD]) age was 70.4 (11.4) years and the mean (SD) duration of T2D at baseline was 8.9 (8.3) years.

Overall, $73.3 \%$ of the population had a history of hypertension. Other recorded comorbidities were a history of dyslipidemia (66.3\%), a history of nephropathy (41.1\%), a history of retinopathy $(39.8 \%)$, and a history of neuropathy $(25.3 \%)$. Comorbidities were balanced between the age groups, except for hypertension (a greater proportion in patients aged $>75$ years) and retinopathy (a smaller proportion in patients aged $>75$ years; Table 1 ). Previous insulin treatments were pre-mixed insulin (44.9\%), basal-bolus insulin (40.7\%), and basal insulin (14.4\%). Demographics and baseline characteristics of patients by previous insulin treatments are presented in Table S1 in the Supplementary Material. Mean (SD) duration of T2D was shorter for patients receiving basal-bolus insulin (6.4 [7.7] years) compared with patients receiving pre-mix (10.9 [8.5] years) or basal insulin (9.5 [7.7] years; Table S1). There was a greater proportion of inpatients in the basal-bolus therapy subgroup (80.8\%) 
Table 1 Patient demographics and baseline clinical characteristics

\begin{tabular}{|c|c|c|c|}
\hline & $\begin{array}{l}\text { Aged } \leq 75 \text { years } \\
(n=6858)\end{array}$ & $\begin{array}{l}\text { Aged }>75 \text { years } \\
(n=3940)\end{array}$ & $\begin{array}{l}\text { Total population } \\
(n=10,798)\end{array}$ \\
\hline Age, mean $\pm S D$ (years) & $64.1 \pm 9.4$ & $81.4 \pm 4.0$ & $70.4 \pm 11.4$ \\
\hline Female, $n(\%)$ & $2685(39.2)$ & $1940(49.2)$ & $4625(42.8)$ \\
\hline Inpatient setting, $n(\%)$ & $3507(51.1)$ & $2701(68.6)$ & $6208(57.5)$ \\
\hline $\mathrm{BMI}$, mean $\pm \mathrm{SD}\left(\mathrm{kg} / \mathrm{m}^{2}\right)^{\mathrm{a}}$ & $24.1 \pm 4.8$ & $22.5 \pm 4.2$ & $23.4 \pm 4.6$ \\
\hline $\begin{array}{l}\text { Duration of type } 2 \text { diabetes, mean } \pm S D \\
\text { (years) }\end{array}$ & $8.5 \pm 7.7$ & $9.5 \pm 9.3$ & $8.9 \pm 8.3$ \\
\hline $\mathrm{HbA}_{1 \mathrm{c}}$, mean $\pm \mathrm{SD}(\%)^{\mathrm{b}}$ & $8.4 \pm 1.9$ & $8.4 \pm 1.7$ & $8.4 \pm 1.9$ \\
\hline History of hypertension, $n(\%)$ & $4783(69.7)$ & $3135(79.6)$ & $7918(73.3)$ \\
\hline History of dyslipidemia, $n(\%)$ & $4635(67.6)$ & $2525(64.1)$ & $7160(66.3)$ \\
\hline History of nephropathy, $n$ (\%) & $2870(41.8)$ & $1573(39.9)$ & $4443(41.1)$ \\
\hline History of retinopathy, $n(\%)$ & $2937(42.8)$ & $1359(34.5)$ & $4296(39.8)$ \\
\hline History of neuropathy, $n(\%)$ & $1757(25.6)$ & $975(24.7)$ & $2732(25.3)$ \\
\hline $\begin{array}{l}\text { Total number of concomitant medications, } \\
\text { mean } \pm \mathrm{SD}\end{array}$ & $13.3 \pm 9.9$ & $16.0 \pm 9.6$ & $14.3 \pm 9.8$ \\
\hline \multicolumn{4}{|l|}{ Insulin therapy, $n(\%)$} \\
\hline Pre-mixed insulin & $3142(45.8)$ & $1705(43.3)$ & $4847(44.9)$ \\
\hline Basal-bolus insulin & $2575(37.5)$ & $1825(46.3)$ & $4400(40.7)$ \\
\hline Basal insulin & $1141(16.6)$ & $410(10.4)$ & $1551(14.4)$ \\
\hline
\end{tabular}

$B M I$ body mass index, $S D$ standard deviation

a Baseline BMI measurements: total population $(n=4928)$; patients aged $\leq 75$ years $(n=2755)$; patients aged $>75$ years $(n=2173)$

b Baseline $\mathrm{HbA}_{1 \mathrm{c}}$ measurements: total population $(n=913)$; patients aged $\leq 75$ years $(n=571)$; patients aged $>75$ years $(n=342)$

compared with the pre-mix $(44.4 \%)$ or basal insulin (32.5\%) subgroups (Table S1).

Of the total population, 913 patients had a baseline $\mathrm{HbA}_{1 \mathrm{c}}$ measurement; the mean (SD) baseline $\mathrm{HbA}_{1 \mathrm{c}}$ was 8.4 (1.9)\%. Demographics and baseline characteristics for patients with a baseline $\mathrm{HbA}_{1 \mathrm{c}}$ measurement were similar to those of the total population (Table S2).

\section{Glycemic Control}

Switching to IDegAsp was associated with statistically significantly improved $\mathrm{HbA}_{1 \mathrm{c}}$ values comparing the estimated change from baseline data at 12 months $(-1.23 \%$ $[-1.43,-1.02]_{95 \% \mathrm{CI}}, \quad p<0.001 ; \quad$ Fig. 1$)$. Improvements in glycemic control appeared numerically similar for patients aged $\leq 75$ years and for patients aged $>75$ years (Fig. 1).

There were numerical differences in the improvement in $\mathrm{HbA}_{1 \mathrm{c}}$ by baseline insulin regimen at 12 months (Table S3); however, statistical analyses were not conducted because of the small numbers of patients in each subgroup.

The proportion of patients with an $\mathrm{HbA}_{1 \mathrm{c}}$ $<8.0 \%$ was statistically significantly greater in 


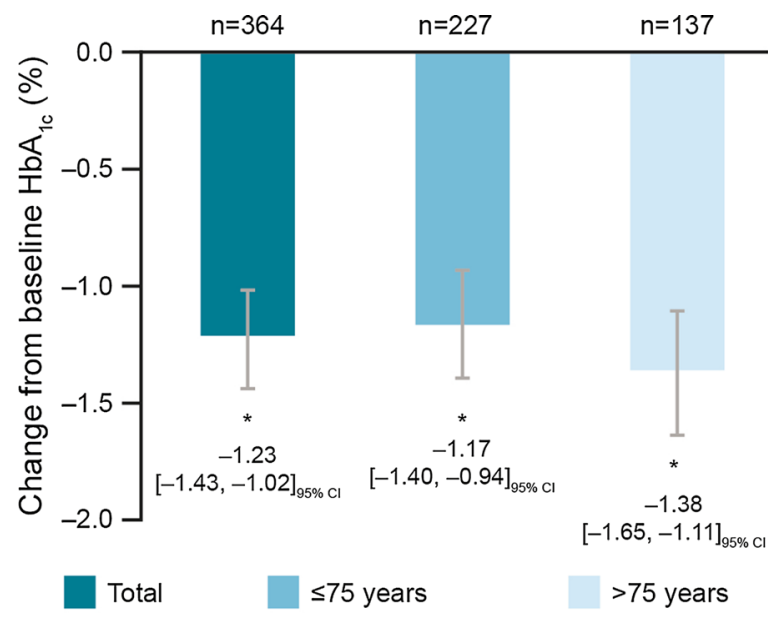

Fig. 1 Estimated mean difference from baseline in $\mathrm{HbA}_{1 \mathrm{c}}$ (\%) at 12 months. LS mean differences were calculated using an MMRM analysis with the following covariates: baseline $\mathrm{HbA}_{1 \mathrm{c}}$, time (grouped by month), previous insulin treatment, age, gender, duration of T2D, and body weight. ${ }^{*} p<0.001$ versus baseline. CI confidence interval, LS least-squares, MMRM mixed model repeated measurements, T2D type 2 diabetes

IDegAsp-treated patients with 12-month data compared with baseline values (relative rate $1.28[1.15,1.43]_{95 \% \mathrm{CI}}, p<0.001$; Fig. $2 \mathrm{a}$ ). The increased proportion of patients with an $\mathrm{HbA}_{1 \mathrm{c}}<8.0 \%$ with IDegAsp treatment compared with baseline values was observed for patients aged $\leq 75$ years and for patients aged $>75$ years at 12 months (Fig. 2a).

The proportions of patients with an $\mathrm{HbA}_{1 \mathrm{c}}<7.5 \%$ and $<7.0 \%$ are presented in Fig. $2 b$ and Fig. 2c; similar trends were observed as for the proportion of patients with an $\mathrm{HbA}_{1 \mathrm{c}}<8.0 \%$.

\section{Hypoglycemia}

At 12 months, the proportion of patients experiencing at least one hypoglycemic event was statistically significantly smaller after IDegAsp treatment compared with baseline $(2.1 \%$ vs $2.6 \%$; relative risk $0.80[0.67,0.95]_{95 \% \mathrm{CI}}$, $p=0.011$ ). When assessed by baseline insulin regimen, the proportions of patients experiencing at least one hypoglycemic event at 12 months versus baseline were $1.8 \%$ versus $2.5 \%$ (pre-mixed insulin), $2.8 \%$ versus $3.0 \%$ (a)
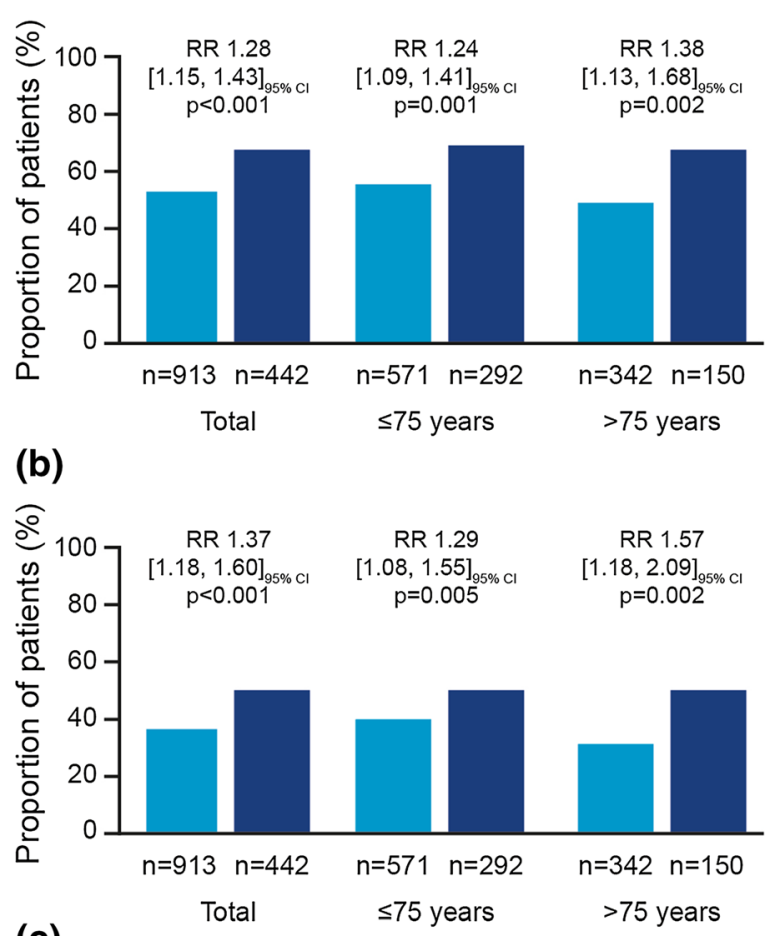

(c)

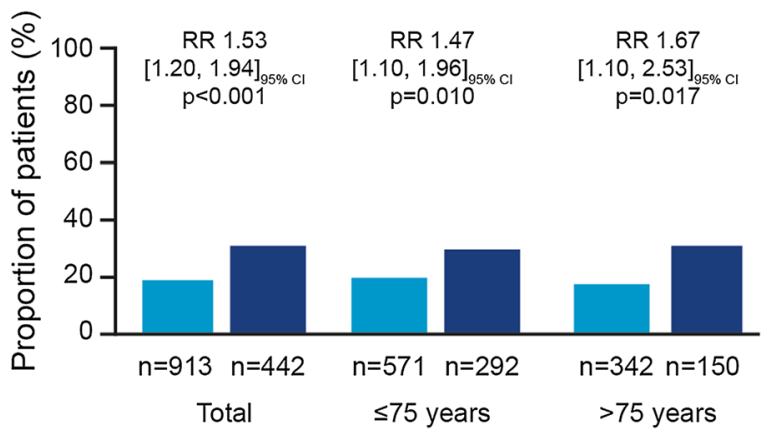

Baseline (pre-treatment) —IDegAsp (post-index)

Fig. 2 Proportion of patients and relative rate of achieving an $\mathrm{HbA}_{1 \mathrm{c}}<8.0 \%$ (a), $<7.5 \%$ (b), and $<7.0 \%$ (c) at baseline and 12 months. CI confidence interval, IDegAsp insulin degludec/insulin aspart, $n$ number of people with an $\mathrm{HbA}_{1 \mathrm{c}}$ measurement, $\mathrm{RR}$ relative rate versus baseline (pre-treatment)

(basal-bolus insulin), and $1.0 \%$ versus $2.1 \%$ (basal insulin).

Switching to IDegAsp treatment was associated with a significantly lower rate of hypoglycemia compared with baseline in patients with 12-month data (rate ratio 0.83 [0.75, $0.91]_{95 \% \mathrm{CI}}, p<0.001$; Fig. 3$)$. A similar trend 


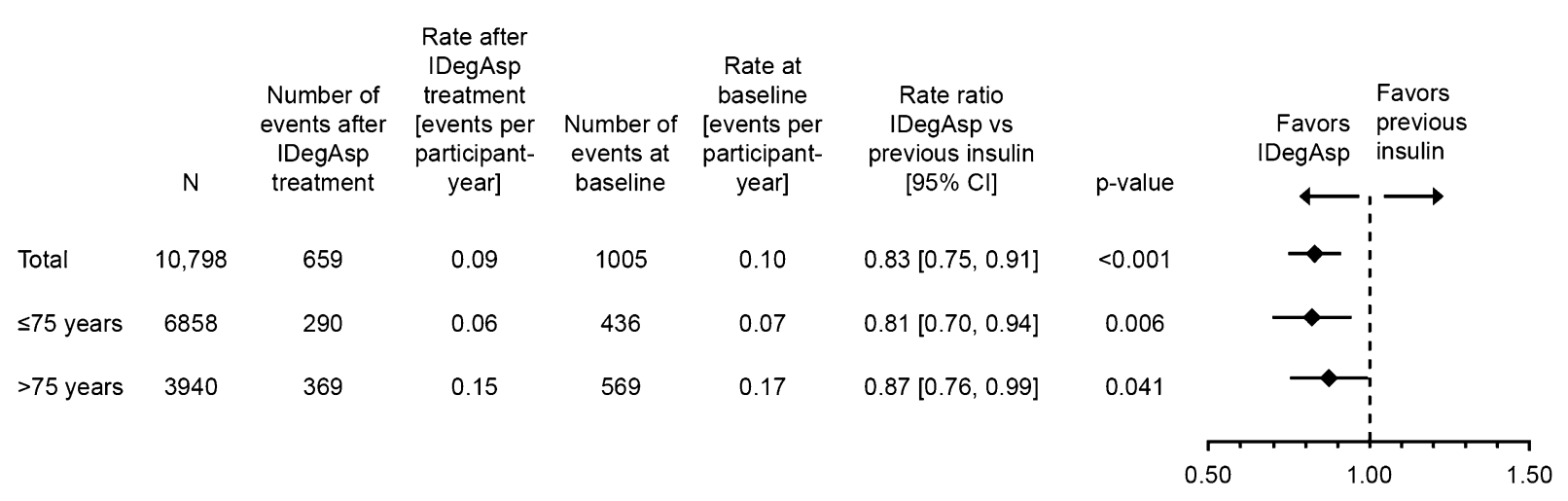

Fig. 3 Rate ratios of hypoglycemia. Hypoglycemia rate ratios at 12 months were based on the total number of hypoglycemic events in the 365 days after the index date (12-month data) compared with the available data 365 days prior to the index date. Rate ratios were

was observed for patients aged $\leq 75$ years and for patients aged $>75$ years (Fig. 3). Descriptive data for the rate of hypoglycemia, at baseline and 12 months, by baseline insulin regimen are presented in Table $\$ 4$.

\section{Composite Endpoints}

Switching to IDegAsp treatment was associated with a significantly greater proportion of patients achieving $\mathrm{HbA}_{1 \mathrm{c}}<8.0 \%,<7.5 \%$, or $<7.0 \%$ without experiencing hypoglycemia when comparing the available 6-month data and 12-month data with baseline values (Fig. 4). This was observed for the dual composite endpoint with all three $\mathrm{HbA}_{1 \mathrm{c}}$ cutoffs: $<8.0 \%(66 \%$ vs $51 \%$ at 12 months), $<7.5 \%$ (49\% vs $36 \%$ at 12 months), and $<7.0 \% \quad(28 \%$ vs $19 \%$ at 12 months). Similar results were observed for patients aged $\leq 75$ years and for patients aged $>75$ years (Fig. 4 ).

\section{Concomitant Medication}

In the overall population, the proportion of people receiving at least one prescription of glucagon-like peptide 1 (GLP-1) receptor agonists, dipeptidyl peptidase 4 (DPP4) inhibitors, sulfonylureas, or sodium/glucose co-transporter 2 (SGLT2) inhibitors was similar 365 days before, and 365 days after, the index date calculated using a generalized linear model with negative binomial distribution. CI confidence interval, IDegAsp insulin degludec/insulin aspart

(Fig. S2). The most commonly received concomitant medications were DPP4 inhibitors: $56 \%$ of patients were receiving at least one prescription of DPP4 inhibitors 365 days prior to the index date and $61 \%$ were receiving at least one prescription 365 days after the index date (Fig. S2). The total numbers of concomitant medications received at 12 months are presented in Table S5.

\section{DISCUSSION}

This study provides the first real-world evidence of the effects of IDegAsp in elderly Japanese patients, using inpatient and outpatient administrative data from the MDV database. The study demonstrated that, in Japanese patients with T2D previously receiving insulin, switching to IDegAsp treatment was associated with significant reductions in $\mathrm{HbA}_{1 \mathrm{c}}$ and rates of hypoglycemic events based on the differences between 12-month data and baseline data. These results were observed both for patients aged $<75$ years and for patients aged $\geq 75$ years.

In the current study, the mean baseline $\mathrm{HbA}_{1 \mathrm{c}}$ was $8.4 \%$, reflecting that many patients in this cohort had suboptimal glycemic control on their original insulin treatment, which would have been one of the reasons for being switched to IDegAsp. The reduction in $\mathrm{HbA}_{1 \mathrm{c}}$ in 
(a)

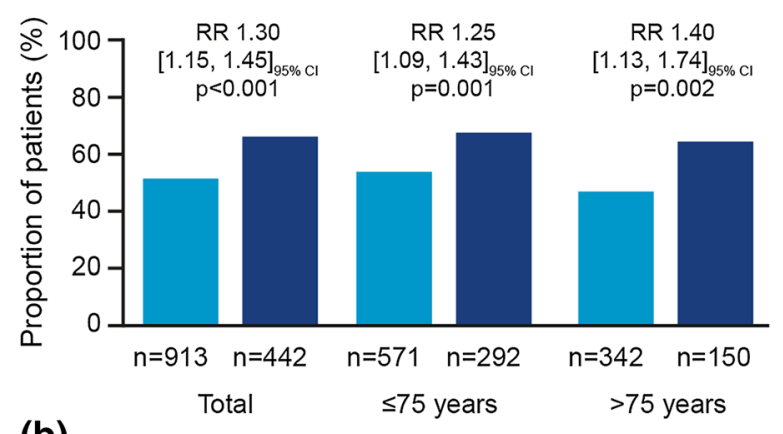

(b)

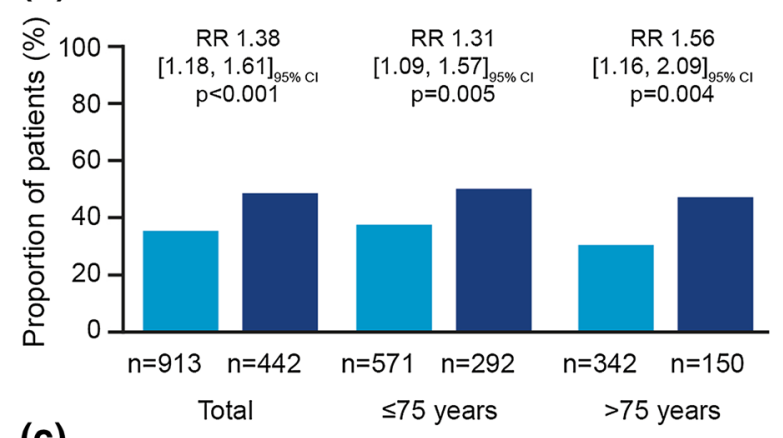

(c)

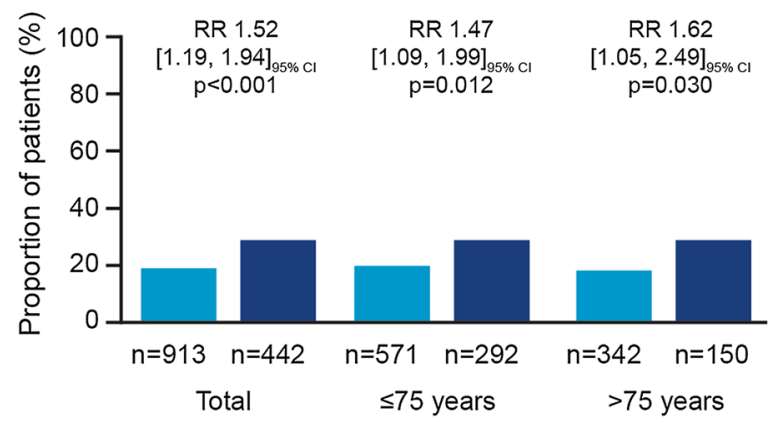

Baseline (pre-treatment)

IDegAsp (post-index)

Fig. 4 Proportion of patients and relative rate of achieving the dual composite outcome of an $\mathrm{HbA}_{1 \mathrm{c}}<8.0 \%$ $(\mathbf{a}),<7.5 \%$ (b), and $<7.0 \%$ (c), without experiencing hypoglycemia. Hypoglycemia events as defined in the Supplementary Material. CI confidence interval, IDegAsp insulin degludec/insulin aspart, RR relative rate

the current real-world study at 12 months $(-1.23 \%)$ was similar to that observed in a subgroup of Japanese patients from a 6-month treat-to-target RCT conducted in patients with T2D inadequately controlled on insulin when treated with IDegAsp $(-1.40 \%)$ [21]. The baseline $\mathrm{HbA}_{1 \mathrm{c}}(8.3 \%)$ in that RCT was similar to that in our study; however, the proportion of patients achieving an $\mathrm{HbA}_{1 \mathrm{c}}<7.0 \%$ was $29.9 \%$ in our study compared with $52.5 \%$ in patients treated with IDegAsp in the study by Taneda et al. [21]. These differences are likely due to both the treat-to-target study design and the fact that the population in the RCT was younger, and therefore expected to achieve this target more easily. Overall, the results of this real-world study show that the potential benefits demonstrated in an RCT setting translate into clinical benefits in the real world.

Patients switched from either pre-mixed insulin, basal-bolus insulin, or basal insulin. Considering basal-bolus insulin is efficacious in reducing $\mathrm{HbA}_{1 \mathrm{c}}$ [22], the substantial improvement in glycemic control despite many patients switching from this regimen may not be expected. However, patients included in this real-world study had likely been switched because their regimen was not adequate for their requirements. It is likely that patients receiving basal-bolus insulin in this cohort found their regimen problematic, possibly as a result of adherence [23] and/or hypoglycemia [24].

The magnitude of $\mathrm{HbA}_{1 \mathrm{c}}$ reduction in elderly patients should always be carefully considered. Indeed, the Japan Diabetes Society (JDS)/Japan Geriatrics Society (JGS) Joint Committee report recommends an $\mathrm{HbA}_{1 \mathrm{c}}$ target of $<8.0 \%$ (lower limit, $7.0 \%$ ) for patients aged $\geq 75$ years with intact cognitive function and no impairment of activities of daily living who use medication potentially associated with severe hypoglycemia (e.g., insulins, sulfonylureas, or glinides) [25]. This follows the findings of the ACCORD study, which evaluated patients with T2D who had either established cardiovascular disease or additional cardiovascular risk factors [26]. Intensive insulin therapy $\left(\mathrm{HbA}_{1 \mathrm{c}}\right.$ target of $<6.0 \%$ ) for 3.5 years increased mortality compared with standard therapy $\left(\mathrm{HbA}_{1 \mathrm{c}}\right.$ target of 7.0-7.9\%) [26]. One possible factor affecting this association was the higher rate of hypoglycemia with intensive insulin therapy compared with standard therapy [26]. However, in the current study, despite the decrease in $\mathrm{HbA}_{1 \mathrm{c}}$, statistically significant reductions in the rate of hypoglycemia at 12 months were observed compared with baseline in both people aged $\leq 75$ years and those aged $>75$ years. 
Furthermore, a significantly greater proportion of people achieved an $\mathrm{HbA}_{1 \mathrm{c}}<8.0 \%,<7.5 \%$, or $<7.0 \%$ without experiencing hypoglycemia at month 12 compared with baseline. This was observed for all $\mathrm{HbA}_{1 \mathrm{c}}$ cutoffs $(<8.0 \%,<7.5 \%$, and $<7.0 \%$ ) and for people aged $\leq 75$ years and people aged $>75$ years.

There are challenges when assessing hypoglycemia in real-world studies. In elderly patients, symptoms of hypoglycemia are not always apparent and are typically under-reported by patients and healthcare professionals [17]. In this study, only events of hypoglycemia identified by an ICD-10 code were included in the analyses; these were the hypoglycemic events that justified admission to an acute care hospital. The recorded events are therefore likely to be the most severe in nature. The frequency of hypoglycemia observed, as per this definition, in the current real-world study was $2.6 \%$ at baseline (pre-index) and $2.1 \%$ at 12 months post-index; these values are similar to those observed in real-world studies and RCTs. In the EUropean TREsiba AudiT (EUTREAT) study, the proportion of patients experiencing at least one severe hypoglycemic event whilst receiving basal insulin was 3.6\%. During the 12 months after switching basal insulin to insulin degludec, the proportion of patients experiencing at least one severe hypoglycemic event was $0.2 \%$ [27], although it should be noted that the data collection method differed from that of the current study. The Step-by-Step study was a randomized, treat-to-target trial in adults with $\mathrm{T} 2 \mathrm{D}$, previously treated with basal insulin \pm oral antidiabetic drugs [28]. Over the 38 -week treatment period (which included the option of intensification from once-daily IDegAsp to twice-daily IDegAsp), the proportion of patients experiencing at least one severe hypoglycemic event was $1.9 \%$. As only the most severe events of hypoglycemia were recorded in this study, the results may not accurately represent the impact of the decrease in $\mathrm{HbA}_{1 \mathrm{c}}$ on hypoglycemia in this elderly population. Nevertheless, the study findings contribute to the currently available IDegAsp evidence in the literature.

This is the largest real-world study to date in any population assessing the impact of IDegAsp on glycemic control $(n=10,798)$; previous realworld reports have included much smaller numbers of patients $(n=5$ [3], $n=22$ [29], $n=48$ [30]). The inclusion criteria were intentionally broad to reflect routine clinical practice and the Japanese population with T2D as closely as possible. The results are therefore intended to be more informative and relevant to clinicians than RCT data, which tend to reflect narrow inclusion criteria and have limited external validity. A further strength of this study was that the sample allowed for a subanalysis of patients aged $>75$ years. Considering the increased risk of hypoglycemia in elderly patients and the ageing population of Japan [16], the opportunity to evaluate the safety and effectiveness of IDegAsp in this population was particularly relevant for Japanese clinical practice.

This study had limitations commonly associated with real-world, retrospective studies, including selection bias and the inability to establish temporal relationships. A further limitation of the study was the relatively low proportion of people with $\mathrm{HbA}_{1 \mathrm{c}}$ recorded at baseline $(n=913)$. The outcomes of difference in $\mathrm{HbA}_{1 \mathrm{c}}$, proportion of patients with $\mathrm{HbA}_{1 \mathrm{c}}$ $<8.0 \%,<7.5 \%$, or $<7.0 \%$, and proportion of patients achieving the dual composite outcomes were assessed using this subset of patients. This potentially limits the generalizability of the results and the number of possible confounders to include in the statistical model. However, demographics and baseline characteristics were assessed for those patients with a baseline $\mathrm{HbA}_{1 \mathrm{c}}$ measurement and were relatively similar to those of the total population.

The proportion of patients with at least one prescription of concomitant medication was similar after initiation of IDegAsp compared with before switching to IDegAsp. However, the data do not describe how much concomitant medication was used. Similarly, the dose of IDegAsp and previous insulin treatments was not recorded. Lastly, the duration of T2D was calculated on the basis of the first diagnosis of T2D in the database. 


\section{CONCLUSIONS}

In this real-world study of Japanese patients with T2D, switching from a previous insulin regimen to IDegAsp was associated with significantly improved glycemic control and a reduction in the rate of hypoglycemia when comparing differences between 12-month follow-up data and baseline data. These findings indicate that IDegAsp may be a suitable treatment option for Japanese patients with T2D, including elderly patients.

\section{ACKNOWLEDGEMENTS}

We thank Lei Liu and Esther Zimmermann (Novo Nordisk) for their review and input to the manuscript.

Funding. Sponsorship for this analysis, and the journal's Rapid Service Fee and Open Access Fee, were funded by Novo Nordisk A/S.

Medical Writing and/or Editorial Assistance. Medical writing and editorial support, under the guidance of the authors, was provided by Matthew Robinson and Beverly La Ferla from Watermeadow Medical, an Ashfield company, part of UDG Healthcare plc, funded by Novo Nordisk.

Authorship. All named authors meet the International Committee of Medical Journal Editors (ICMJE) criteria for authorship for this article, take responsibility for the integrity of the work as a whole, and have given their approval for this version to be published. All named authors also confirm that they have contributed to the critical analysis and interpretation of the data, drafting/critically revising the manuscript and share in the final responsibility for the content of the manuscript and the decision to submit it for publication.

Authorship Contributions. Shizuka Kaneko is the guarantor of this work and, as such, had full access to all the data in the study, and takes responsibility for the integrity of the data and the accuracy of the data analysis. João Diogo da Rocha Fernandes and Mads Faurby were involved in data curation; formal analysis; methodology; validation.

Disclosures. Shizuka Kaneko has received honoraria for speakers bureau from AstraZeneca K.K.; Sumitomo Dainippon Pharma; Eli Lilly Japan K.K.; Mitsubishi Tanabe Pharma; Novo Nordisk; Ono Pharmaceutical; Taisho Toyama Pharmaceutical; and grants from WebMD Global LLC. João D. da Rocha Fernandes, Yuiko Yamamoto, and Mads Faurby are employees at Novo Nordisk and shareholders of Novo Nordisk. Jakob Langer is an employee at Novo Nordisk.

Compliance with Ethics Guidelines. For this retrospective database study, all data for analysis were extracted from a pre-existing anonymized database and permission was granted to access the data and to use them for publication purposes. For the usage of de-identified secondary data, ethical approval and informed consent do not apply according to the Japanese Ethical Guidelines for Medical and Health Research Involving Human Subjects [31].

Data Availability. The datasets generated and/or analyzed during the current study are available from the corresponding author on reasonable request.

Open Access. This article is licensed under a Creative Commons Attribution-NonCommercial 4.0 International License, which permits any non-commercial use, sharing, adaptation, distribution and reproduction in any medium or format, as long as you give appropriate credit to the original author(s) and the source, provide a link to the Creative Commons licence, and indicate if changes were made. The images or other third party material in this article are included in the article's Creative Commons licence, unless indicated otherwise in a credit line to the material. If material is not included in the article's Creative Commons licence and your intended use is not permitted by statutory regulation or exceeds the permitted use, you will need to obtain permission directly from the 
copyright holder. To view a copy of this licence, visit http://creativecommons.org/licenses/bync/4.0/.

\section{REFERENCES}

1. Haneda $M$, Noda $M$, Origasa $H$, et al. Japanese clinical practice guideline for diabetes 2016. Diabetol Int. 2018;9:1-45.

2. Tanaka S, Tanaka S, Iimuro S, et al. Predicting macro- and microvascular complications in type 2 diabetes: the Japan Diabetes Complications Study/ the Japanese Elderly Diabetes Intervention Trial risk engine. Diabetes Care. 2013;36:1193-9.

3. Kalra S. Insulin degludec and insulin degludec/insulin aspart in Ramadan: a single center experience. Indian J Endocrinol Metab. 2016;20:564-7.

4. Meece J. Basal insulin intensification in patients with type 2 diabetes: a review. Diabetes Ther. 2018;9:877-90.

5. Iglay K, Hannachi H, Joseph Howie P, et al. Prevalence and co-prevalence of comorbidities among patients with type 2 diabetes mellitus. Curr Med Res Opin. 2016;32:1243-52.

6. Mosenzon O, Raz I. Intensification of insulin therapy for type 2 diabetic patients in primary care: basal-bolus regimen versus premix insulin analogs: when and for whom? Diabetes Care. 2013;36(Suppl. 2):S212-8.

7. Kachroo S, Kawabata H, Colilla S, et al. Association between hypoglycemia and fall-related events in type 2 diabetes mellitus: analysis of a U.S. commercial database. J Manag Care Spec Pharm. 2015;21:243-53.

8. European Medicines Agency. Ryzodeg (insulin degludec/insulin aspart) summary of product characteristics 2019. https://www.ema.europa.eu/en/ documents/product-information/ryzodeg-eparproduct-information_en.pdf. Accessed Feb 2020.

9. Heise T, Nosek L, Roepstorff C, Chenji S, Klein O, Haahr H. Distinct prandial and basal glucose-lowering effects of insulin degludec/insulin aspart (IDegAsp) at steady state in subjects with type 1 diabetes mellitus. Diabetes Ther. 2014;5:255-65.

10. Fulcher GR, Christiansen JS, Bantwal G, et al. Comparison of insulin degludec/insulin aspart and biphasic insulin aspart 30 in uncontrolled, insulintreated type 2 diabetes: a phase $3 a$, randomized, treat-to-target trial. Diabetes Care. 2014;37: 2084-90.

11. Kaneko S, Chow F, Choi DS, et al. Insulin degludec/ insulin aspart versus biphasic insulin aspart 30 in Asian patients with type 2 diabetes inadequately controlled on basal or pre-/self-mixed insulin: a 26-week, randomised, treat-to-target trial. Diabetes Res Clin Pract. 2015;107:139-47.

12. Onishi Y, Ono Y, Rabøl R, Endahl L, Nakamura S. Superior glycaemic control with once-daily insulin degludec/insulin aspart versus insulin glargine in Japanese adults with type 2 diabetes inadequately controlled with oral drugs: a randomized, controlled phase 3 trial. Diabetes Obes Metab. 2013;15: 826-32.

13. Park SW, Bebakar WM, Hernandez PG, Macura S, Herslov ML, de la Rosa R. Insulin degludec/insulin aspart once daily in type 2 diabetes: a comparison of simple or stepwise titration algorithms (BOOST ${ }^{\circledR}$ : SIMPLE USE). Diabet Med. 2017;34:174-9.

14. Fulcher G, Mehta R, Fita EG, Ekelund M, Bain SC. Efficacy and safety of IDegAsp versus BIAsp 30, both twice daily, in elderly patients with type 2 diabetes: post hoc analysis of two phase 3 randomized controlled BOOST trials. Diabetes Ther. 2019;10: 107-18.

15. Blonde L, Khunti K, Harris SB, Meizinger C, Skolnik NS. Interpretation and impact of real-world clinical data for the practicing clinician. Adv Ther. 2018;35: 1763-74.

16. Cabinet Office Government of Japan. Annual Report on the Aging Society: 2019. 2019. https:// www8.cao.go.jp/kourei/english/annualreport/ 2019/pdf/2019.pdf. Accessed Feb 2020.

17. Abdelhafiz AH, Rodriguez-Manas L, Morley JE, Sinclair AJ. Hypoglycemia in older people-a less well recognized risk factor for frailty. Aging Dis. 2015;6: 156-67.

18. Medical Data Vision. Introducing MDV Database 2019. https://www.mdv.co.jp/mdv_database/ english/. Accessed Feb 2020.

19. Ministry of Health Labour and Welfare (Japan). Ministry of Health, Labour and Welfare, and Ministry of Education, Culture, Sports, Science and Technology. Ethical Guidelines for Medical and Health Research Involving Human Subjects 2015. https://www.mhlw.go.jp/file/06-Seisakujouhou10600000-Daijinkanboukouseikagakuka/ 0000080278.pdf. Accessed Feb 2020.

20. ICD.Codes. ICD-10-CM Code E16.0 2019. https:// icd.codes/icd10cm/E160. Accessed Feb 2020. 
21. Taneda S, Hyllested-Winge J, Gall MA, Kaneko S, Hirao K. Insulin degludec/insulin aspart versus biphasic insulin aspart 30 twice daily in insulinexperienced Japanese subjects with uncontrolled type 2 diabetes: subgroup analysis of a pan-Asian, treat-to-target phase 3 trial. J Diabetes. 2017;9: 243-7.

22. Hong T, Lu J, Zhang P, et al. Efficacy and safety of basal analog regimens in type 2 diabetes mellitus: systematic review and meta-analysis of randomized controlled trials. Diabetes Ther. 2019;10:1051-66.

23. Pfeiffer KM, Basse A, Lee XY, Waldman LT. Diabetes management and healthcare resource use when intensifying from basal insulin to basal-bolus: a survey of type 2 diabetes patients. Diabetes Ther. 2018;9:1931-44.

24. Bellido V, Suarez L, Rodriguez MG, et al. Comparison of basal-bolus and premixed insulin regimens in hospitalized patients with type 2 diabetes. Diabetes Care. 2015;38:2211-6.

25. Japan Diabetes Society (JDS)/Japan Geriatrics Society (JGS) Joint Committee on Improving Care for Elderly Patients with Diabetes. Committee Report: Glycemic targets for elderly patients with diabetes. J Diabetes Investig. 2017;8:126-8.

26. Gerstein HC, Miller ME, Byington RP, et al. Effects of intensive glucose lowering in type 2 diabetes. N Engl J Med. 2008;358:2545-59.
27. Siegmund T, Tentolouris N, Knudsen ST, et al. A European, multicentre, retrospective, non-interventional study (EU-TREAT) of the effectiveness of insulin degludec after switching basal insulin in a population with type 1 or type 2 diabetes. Diabetes Obes Metab. 2017;20:689-97.

28. Philis-Tsimikas A, Astamirova K, Gupta Y, et al. Similar glycaemic control with less nocturnal hypoglycaemia in a 38-week trial comparing the IDegAsp co-formulation with insulin glargine U100 and insulin aspart in basal insulin-treated subjects with type 2 diabetes mellitus. Diabetes Res Clin Pract. 2019;147:157-65.

29. Fujimoto K, Iwakura T, Aburaya M, Matsuoka N. Twice-daily insulin degludec/insulin aspart effectively improved morning and evening glucose levels and quality of life in patients previously treated with premixed insulin: an observational study. Diabetol Metab Syndr. 2018;10:64.

30. Kalra S, Baruah MP. Insulin degludec aspart: oneyear real world experience. Indian J Endocrinol Metab. 2016;20:369-71.

31. Ministry of Health, Labour and Welfare, and Ministry of Education, Culture, Sports, Science and Technology. Ethical Guidelines for Medical and Health Research Involving Human Subjects, 2015. https://www.mhlw.go.jp/file/06-Seisakujouhou10600000-Daijinkanboukouseikagakuka/ 0000080278.pdf. Accessed Feb 2020. 